\title{
Breastfeeding media coverage and beliefs during the COVID-19 pandemic in Mexico: implications for breastfeeding equity
}

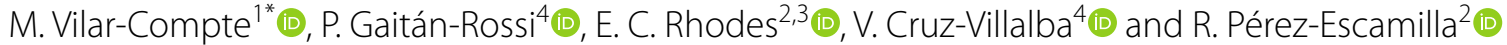

\begin{abstract}
Background: Because breastfeeding offers short- and long- term health benefits to mothers and children, breastfeeding promotion and support is a public health priority. Evidence shows that SARS-CoV-2 is not likely to be transmitted via breastmilk. Moreover, antibodies against SARS-CoV-2 are thought to be contained in breastmilk of mothers with history of COVID-19 infection or vaccination. WHO recommends direct breastfeeding as the preferred infant feeding option during the COVID-19 pandemic, even among women with COVID-19; but conflicting practices have been adopted, which could widen existing inequities in breastfeeding. This study aims to describe how information about breastfeeding was communicated in Mexican media during the pandemic and assess Mexican adults' beliefs regarding breastfeeding among mothers infected with COVID-19.

Methods: We conducted a retrospective content analysis of media coverage on breastfeeding in Mexico between March 1 and September 24, 2020, excluding advertisements. For the content analysis, we performed both a sentiment analysis and an analysis based on strengths, weaknesses, opportunities, and threats (SWOT) for breastfeeding promotion. Additionally, we conducted a descriptive analysis of nationally representative data on adults' beliefs about breastfeeding from the July 2020 round of the ENCOVID-19 survey in Mexico and stratified the results by gender, age, and socioeconomic status.
\end{abstract}

Results: A total of 1014 publications on breastfeeding were identified on the internet and television and in newspapers and magazines. Most information was published during World Breastfeeding Week, celebrated in August. The sentiment analysis showed that $57.2 \%$ of all information was classified as positive. The SWOT analysis indicated that most information focused on current actions, messages, policies, or programs that enable breastfeeding (i.e., strengths) or those not currently in place but that may enable breastfeeding (i.e., opportunities) for breastfeeding promotion. However, ENCOVID-19 survey results showed that $67.3 \%$ of adults living in households with children under 3 years of age believe that mothers with COVID-19 should not breastfeed, and 19.8\% do not know whether these mothers should breastfeed. These beliefs showed differences both by gender and by socioeconomic status.

Conclusions: While the Mexican government endorsed the recommendation on breastfeeding during the COVID19 pandemic, communication was sporadic, inconstant and unequal across types of media. There was a widespread notion that mothers with COVID-19 should not breastfeed and due to differences on beliefs by socioeconomic status,

*Correspondence: vilarcomptem@montclair.edu

${ }^{1}$ Department of Public Health, Montclair State University, University Hall

4157, 1 Normal Ave, Montclair, NJ 07043, USA

Full list of author information is available at the end of the article original author(s) and the source, provide a link to the Creative Commons licence, and indicate if changes were made. The images or other third party material in this article are included in the article's Creative Commons licence, unless indicated otherwise in a credit line to the material. If material is not included in the article's Creative Commons licence and your intended use is not permitted by statutory regulation or exceeds the permitted use, you will need to obtain permission directly from the copyright holder. To view a copy of this licence, visit http://creativecommons.org/licenses/by/4.0/. The Creative Commons Public Domain Dedication waiver (http://creativeco mmons.org/publicdomain/zero/1.0/) applies to the data made available in this article, unless otherwise stated in a credit line to the data. 
health inequities could be exacerbated by increasing the risk of poorer breastfeeding practices and preventing vulnerable groups from reaping the short and long-term benefits of breastfeeding.

Keywords: Breastfeeding, COVID-19, Infant feeding, Inequities, Media analysis

This article is a part of the Interventions and policy approaches to promote equity in breastfeeding collection, guest-edited by Rafael Pérez-Escamilla, PhD and Mireya Vilar-Compte, PhD

\section{Background}

The protection, promotion, and support of breastfeeding is a priority for public health, since breastfeeding offers mothers and children a constellation of short- and long-term health benefits $[1,2]$. Evidence has consistently shown that the severe acute respiratory syndrome coronavirus 2 (SARS-CoV-2) is not likely to be transmitted via breastmilk (i.e., vertical transmission) [3-11]. In addition, COVID-19 appears to be less prevalent and, generally, less severe in infants $[12,13]$. There is evidence that breastmilk from mothers with a history of COVID19 infection contains antibodies against SARS-CoV-2, including Immunoglobulin A (IgA) and Immunoglobulin G (IgG) [12, 14-19]. It has been hypothesized that these antibodies may offer an infant protection against COVID-19, though more research - including studies with larger samples and longer follow-up periods - is needed to confirm this, since the magnitude, functionality, and durability of the breastmilk immune response is still unknown [15]. Furthermore, prospective cohort studies have found that anti-SARS-CoV-2 IgA and IgG generated by anti-COVID-19 mRNA-based vaccines administered to lactating and pregnant mothers are transferred to their babies via breastmilk $[14,20,21]$ and umbilical cord blood [22, 23], while COVID-19 mRNA is not transferred [14, 24, 25].

Breastmilk contains anti-microbial and anti-inflammatory factors that promote the development of the immune system and protects them from pneumonia, diarrhea, and other poor health conditions [26, 27]. Accounting for this evidence, and the short and longterm harm resulting from the separation of the motherchild dyad during the perinatal period, as well as the susceptibility of newborns to person-to-person spread of COVID-19 through contact with mothers and caregivers (i.e., horizontal transmission) [12], the World Health Organization (WHO) recommends that women with COVID-19 should breastfeed their babies [10, 12, 28] and that feeding directly from the breast, referred to as direct breastfeeding, should be supported as the preferred recommended infant feeding option during the pandemic. Accordingly, mothers with confirmed or suspected COVID-19 should be informed about the importance of continued direct breastfeeding. During the birth hospitalization period, mother-infant dyads should be cared for together, including skin-to-skin contact and room sharing, which is critical for helping mothers establish and continue breastfeeding [13]. Separating mothers and their infants during this time increases neonatal morbidity and mortality [29].

Despite the WHO's strong emphasis on promoting breastfeeding and keeping the mother-infant dyad together in the hospital immediately after birth during the COVID-19 pandemic, some governments, professional organizations, and hospitals have not adopted these practices [30]. During the early stages of the pandemic, recommendations against practices supportive of breastfeeding were common, even in countries with high infant mortality rates [31]. For example, some governments and health care systems recommended that infected mothers be separated from their infants after birth to reduce the risk of infant COVID-19 infection. Inconsistencies in guidance from reputable international and professional agencies such as the Centers for Diseases Control and Prevention (CDC) in the United States and medical associations such as the American College of Obstetricians and Gynecologists (ACOG) may have contributed to the misalignment with WHO recommendations in countries and healthcare facilities. Moreover, such recommendations generated uncertainty about breastfeeding among new parents $[13,32]$. Sola et al. analyzed evidence from 7 countries of the Ibero American Society of Neonatology (Argentina, Colombia, Ecuador, Equatorial Guinea, Honduras, Peru and Dominican Republic) from March to May 2020 to evaluate how the pandemic impacted pregnant and breastfeeding women and newborns in Latin America [33]. Findings showed that lack of breastfeeding support and mother-infant dyad separation among COVID-19 positive women were common during the early months of the pandemic, as well as increased practices of formula feeding.

Furthermore, despite the emerging evidence suggesting that it is safe to breastfeed after receiving the COVID-19 vaccine [34] and that doing so may benefit both mothers and infants [23], initial vaccination policies denied breastfeeding women's access to the vaccine. These policies were created due to possible safety concerns, which could not be ruled out because breastfeeding women were not included in vaccine trials. Indeed, some federal and local governments and COVID-19 
vaccination centers in different countries [34-36], initially required consent forms or disseminated fact sheets stating that mothers who receive the COVID-19 vaccine should not breastfeed or mothers should contact their healthcare providers to further discuss the safety of the vaccine during breastfeeding. This guidance may have led healthcare providers to not promote and support breastfeeding and may have discourge mothers not to breastfeed their infants [37], even after such guidance was later reversed [38].

Diverse pre-COVID socio-cultural beliefs about breastfeeding, the uncertainty and social anxiety brought by the pandemic [12], and the marketing strategies from the breastmilk susbtitutes industry during the pandemic might have also prompted healthcare providers and mothers to not start or discontinue breastfeeding during the pandemic. Rising mis and dis-information regarding health could have added to the problem. A multi-institutional statement highlighted that the pandemic has produced an infodemic - an overabundance of information, both online and offline, that includes deliberate attempts to disseminate wrong information to undermine the public health response and advance alternative agendas [39]. It is therefore critical to track the extent to which official health authorities' messages during the pandemic spread among the population, as well as the scientific validity of their messages [40]. A previous study found that $6 \%$ of tweets about breastfeeding and COVID-19 that were tweeted up until March 27, 2020 contained scientifically unfounded recommendations or information tailored for commercial use that undermine breastfeeding, such as promotion of breast pumps and feeding bottles [40]. Media can be a powerful tool to promote or discourage breastfeeding not only through dissemination of information, but also as a mechanism for generating public interest and legitimizing a problem [41]. Given its influence, media helps determine which policy issues are most salient to the public [42], and, thus, influence the formation of public agendas [43] and the "public mood" towards a given issue such as breastfeeding during the pandemic. There is little information on media coverage on breastfeeding practices and COVID-19 and its influence on breastfeeding behaviors and beliefs.

Separating mothers from their infants during the birth hospitalization and suggesting mothers not initiate or discontinue breastfeeding to reduce the risk of COVID19 in infants may widen existing inequities in breastfeeding. Socio-economically marginalized groups are least able to stay home during lockdowns and adhere to social distancing guidelines to reduce the spread of COVID-19, due to the nature of their jobs [44]. These groups are, therefore, least able to minimize their viral exposure. They might also be more likely to suffer the adverse consequences of mother-infant separation during the birth hospitalization, and in turn, to face barriers to breastfeeding [45]. Furthermore, vulnerable groups have also suffered disproportionately from the adverse economic consequences of the pandemic, such as job loss and furlough [44]. Hence, breastfeeding in the context of COVID-19 is of increased importance to mitigate household food insecurity, since breastmilk is the most affordable form of infant and young child nutrition and the high cost of BMS can further strain household budgets among families already facing financial stress and reduce funds available for food expenditure [13]. It is also well established that breastmilk provides the cleanest and safest form of infant and young child nutrition during crises, and it is the normative standard for infant nutrition [3]. Hence, breastfeeding should be considered as a fundamental protective and health promotion measure for infants during the pandemic [27].

Mexico has been severely affected by the COVID-19 pandemic; it has the fourth highest number of COVID19 related deaths in the world [46]. The public health emergency in Mexico has had sustained negative effects on household income, employment, food insecurity, and mental health since the beginning of the pandemic in March 2020 [47-49]. Prior to the pandemic, there had been a steady increase in breastfeeding rates in Mexico. For example, the exclusive breastfeeding rate among infants under six months improved from 14.4\% in 2012 to $28.3 \%$ in 2018 [50, 51]. Due to the COVID-19 pandemic, however, these improvements may slow down and widen breastfeeding inequities if actions to promote and protect breastfeeding during this public health emergency are not taken. While the Mexican government [52], the national institutes of pediatrics and perinatology [53], and the Mexican Association of Pediatricians [54] adhered to scientific evidence and WHO guidance on breastfeeding during the COVID-19 pandemic early in the pandemic and established guidelines and pronouncements accordingly, it is unlcear if these guidelines and prouncements were adequately disseminated and implemented. Due to changes in the Federal administration prior to the pandemic, the National Strategy of Breastfeeding [55] had expired and not been renewed. Thus, government commitment and investment in breastfeeding protection, promotion, and support was lacking when the pandemic emerged.

The aims of this study were (a) to describe how Mexican government recommendations on breastfeeding during COVID-19 were communicated in traditional media platforms, including newspaper, magazine, radio, and television, (b) to assess Mexican adults' beliefs regarding breastfeeding among mothers infected with COVID-19, and (c) to assess if there were differences in these beliefs 
by socioeconomic status, with the goal of understanding whether adults who are socio-economically disadvantaged might be more likely to hold views that do not align with current scientific recommendations on breastfeeding compared with adults who are not.

\section{Methods}

The study used two complementary methodological approaches: (a) a retrospective content analysis of media coverage on breastfeeding in print and online media sources in Mexico between March 1 and September 24, 2020 and (b) a descriptive analysis based on nationally representative data from a telephone survey, the Survey on COVID-19 Effects on Wellness in Mexican Households (ENCOVID-19, for its acronym in Spanish).

\section{Analysis of media coverage on breastfeeding}

The analysis included any newspaper, magazine, radio, and television coverage of breastfeeding. Social media was excluded from the analysis because analyzing it requires a different methodological approach. The media search was conducted by Eficiencia Informativa, a company that specializes in media monitoring and content analysis. It was done using a combination of the following key words in Spanish: breastfeeding, maternity leave, Becoming Breastfeeding Friendly (a global initiative to promote, protect, and support breastfeeding in hospitals), and Permanent Interinstitutional Support Group for Breastfeeding (a group led by the Ministry of Health). The inclusion criteria for the media search were: (a) date of publication between March 1 and September 24, 2020; (b) includes information on breastfeeding; (c) published and disseminated in Mexico, and (d) not an advertisement.

The information identified in the media search was organized both by media platform and by date, in order to identify the frequency of documents or programs (i.e., TV and radio) mentioning breastfeeding per month. A thematic analysis was performed, in order to organize the information into key themes. These themes were then analyzed through both a sentiment analysis and an analysis that identifies strengths, weaknesses, opportunities, and threats, which is commonly referred to as a SWOT analysis.

Through the sentiment analysis, each piece of information was classified as positive, neutral, or negative with regards to its potential impact on breastfeeding promotion during the pandemic; examples of such classification can be found in Table 1 .

The SWOT analysis was based on a breastfeeding media analysis methodology previously used in Mexico [56]. The SWOT analysis examined organizational and environmental strengths and weaknesses, opportunities for improvement, and potential threats to breastfeeding promotion during the pandemic. This sort of analysis intends to inform future actions to improve breastfeeding promotion and communication. Two of the authors (MVC, VCV) independently verified the classification of doucments and programs performed by Eficiencia Informativa and generated a SWOT matrix. The operational definitions for each category of the SWOT analysis is presented in Table 2 .

\section{Descriptive analysis of ENCOVID-19 data}

The ENCOVID-19 is a monthly telephone survey that was started in April 2020 to document the consequences of the COVID-19 pandemic in Mexico. With a repeated cross-sectional design, the ENCOVID-19 is administered monthly to a nationally representative sample of individuals 18 years and older who have a mobile phone. Therefore, post-stratification sampling weights were used to correct minor deviations from Mexico's demographic structure.

The ENCOVID-19 survey included two questions on breastfeeding in the July 2020 round. The sample included 1584 individuals and was representative of households with children under 18 years of age. Amongst them, 279 people lived in a household with a child under 3 years old. Participants were asked to respond to the following two questions: "From what you know, if a mother has COVID-19, should she breastfeed?" Response options were Yes, No, and Don't know. If they answered no, the follow-up question was: "What

Table 1 Examples of positive, neutral, and negative sentiment classification for breastfeeding promotion

\begin{tabular}{|c|c|c|}
\hline Positive information & Neutral information & Negative information \\
\hline $\begin{array}{l}\text { Recommendations to continue breastfeeding } \\
\text { during the pandemic }\end{array}$ & $\begin{array}{l}\text { Reports on the importance of traditional mid- } \\
\text { wifery in indigenous communities during the } \\
\text { pandemic }\end{array}$ & $\begin{array}{l}\text { Reports of increase marketing of breastmilk } \\
\text { substitutes during the pandemic }\end{array}$ \\
\hline $\begin{array}{l}\text { Reports of no evidence that COVID-19 can be } \\
\text { transmitted via breastmilk }\end{array}$ & $\begin{array}{l}\text { Reports on decrease in Mexican women's fertility } \\
\text { rate }\end{array}$ & Reports of detection of COVID-19 in breastmilk \\
\hline $\begin{array}{l}\text { Promotion of breastfeeding continuation during } \\
\text { social distancing and lockdown measures by the } \\
\text { Mexican Ministry of Health }\end{array}$ & $\begin{array}{l}\text { Reports on the first births from Mexican mothers } \\
\text { infected with COVID-19 }\end{array}$ & $\begin{array}{l}\text { Reports about health professionals' influence } \\
\text { on the discontinuation of breastfeeding among } \\
\text { mothers }\end{array}$ \\
\hline
\end{tabular}


Table 2 SWOT operational definitions and examples of classification of information based on this analysis

\begin{tabular}{|c|c|c|}
\hline Category & Operational definition $^{a}$ & Example \\
\hline Strengths & $\begin{array}{l}\text { Current actions, messages, policies, or programs that enable } \\
\text { breastfeeding }\end{array}$ & $\begin{array}{l}\text { The Mexican Ministry of Health promoting breastfeeding continu- } \\
\text { ation during the COVID-19 pandemic }\end{array}$ \\
\hline Weaknesses & $\begin{array}{l}\text { Actions, messages, policies, or programs currently in place that } \\
\text { negatively affect breastfeeding }\end{array}$ & $\begin{array}{l}\text { Newborns separated from their mothers during the birth hospitali- } \\
\text { zation due to fear of virus transmission from mothers to newborns. }\end{array}$ \\
\hline Opportunities & $\begin{array}{l}\text { Actions, messages, policies, or programs not currently in place } \\
\text { that may enable breastfeeding }\end{array}$ & $\begin{array}{l}\text { United Nations Children's Fund (UNICEF) Mexico and the Mexican } \\
\text { government initiating a new Cooperation Program for the } \\
\text { 2020-2025 period. }\end{array}$ \\
\hline Threats & $\begin{array}{l}\text { Actions, messages, policies or programs not currently in place that } \\
\text { may negatively affect breastfeeding }\end{array}$ & $\begin{array}{l}\text { The COVID-19 pandemic projected to have collateral effects on } \\
\text { health, not directly associated to the virus transmission, such as } \\
\text { reduction in breastfeeding rates, delay in diagnoses, and mental } \\
\text { health issues }\end{array}$ \\
\hline
\end{tabular}

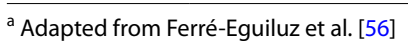

is the reason not to breastfeed?". Response options were: i) The virus is transmitted through breastmilk; ii) $\mathrm{My}$ physician recommended not to; and iii) The mother should be isolated. Although breastfeeding practices are most relevant for this subpopulation, the survey did not capture the perceptions of the general population, which is also exposed to media messages about breastfeeding. Moreover, the respondent of the survey is the person who answered the call and not necessarily the caregiver in the household.

In addition to collecting data on demographic characteristics (sex, age in years), the ENCOVID-19 collects data for calculating the Mexican Association of Market and Opinion Intelligence Agencies (AMAI, for its acronym in Spanish) index [57], an assets-based household socioeconomic index with six indicators, including: (i) education level of the head of household; (ii) number of bathrooms; (iii) number of cars or vans; (iv) having an Internet connection; (v) number of household members 14 years or older who are working, and (vi) number of bedrooms.

Descriptive analyses were conducted to generate frequencies and proportions of responses to each question on breastfeeding by gender, age, and socioeconomic status.

\section{Results}

\section{Analysis of media coverage on breastfeeding}

A total of 1014 mentions of breastfeeding in the context of COVID-19 were identified, with most mentions on the Internet $(83.6 \%)$ followed by newspapers $(10.4 \%)$, television (3.6\%), magazines (1.7\%), and radio (0.8\%) (Table 3$)$. During August 2020 when World Breastfeeding Week was celebrated in Mexico, these mentions spiked, reaching 400 during the entire month (Fig. 1).

More than half of all mentions were classified as positive for breastfeeding promotion (Fig. 2), and in all
Table 3 Mentions of breastfeeding in the context of COVID-19 classified by type of media

\begin{tabular}{ll}
\hline Type of media & Mentions, $\mathbf{n}(\%)$ \\
\hline $\begin{array}{ll}\text { Internet (online versions of newspapers and maga- } \\
\text { zines) }\end{array}$ & $848(83.6 \%)$ \\
Newspapers & $105(10.4 \%)$ \\
TV & $36(3.6 \%)$ \\
Magazines & $17(1.7 \%)$ \\
Radio & $8(0.8 \%)$ \\
\hline
\end{tabular}

media platforms, positive information was higher than negative and neutral information combined, except for information published in magazines, where most of the information on breastfeeding was classified as neutral. It is noteworthy that messages during World Breastfeeding Week in August were more likely to be of a positive nature than messages at other times of the year. In fact, during August 2020 only $5 \%$ of the messages were negative, while $19.75 \%$ were neutral and $75.25 \%$ were positive.

The most prevalent negative theme was the increase of marketing of breastmilk substitutes during the pandemic, informed through news reports about it found on the analyzed media platforms, accounting for 67 $(6.6 \%)$ of total mentions of breastfeeding. Six $(0.6 \%)$ mentions stated that COVID-19 was detected in breastmilk and $4(0.4 \%)$ mentions referred to the influence of advice from medical doctors in women's decisions not to breastfeed. Positive themes on breastfeeding are shown in Table 4.

In accordance with the findings from the sentiment analysis, the SWOT analysis results showed that almost all of the information (84.6\%) promoted breastfeeding; $64.3 \%$ of all mentions were classified as strengths and $20.3 \%$ as opportunities, whereas $11.7 \%$ of them were classified as threats and only $3.6 \%$ as weaknesses. Results from the SWOT analysis are shown in Table 5. 

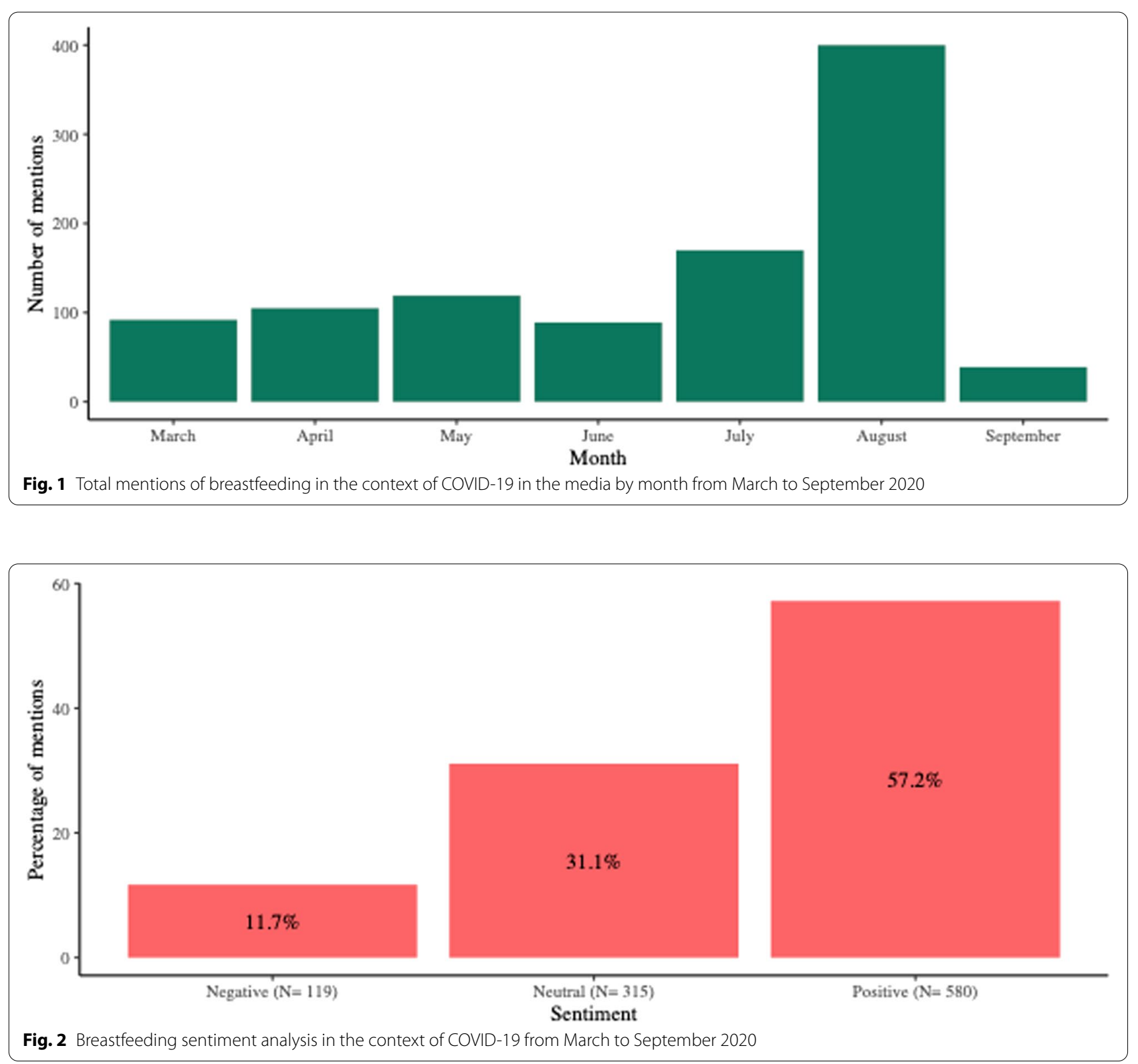

Table 4 Positive themes found about breastfeeding and COVID-19

\begin{tabular}{lc}
\hline Theme & $\begin{array}{c}\text { Mentions, } \\
\text { (\% of total) }\end{array}$ \\
\hline Recommendations to keep breastfeeding during the pandemic & $90(8.9 \%)$ \\
Reports of no evidence that COVID-19 could be transmitted via breastmilk & $51(5 \%)$ \\
Announcement that the Mexican Ministry of Health would promote breastfeeding during social distancing and lockdown measures & $29(2.9 \%)$ \\
Feeding recommendations during the pandemic made from United Nations (UN) agencies to the Mexican government & $12(1.2 \%)$
\end{tabular}

\section{Descriptive analysis of ENCOVID-19 data}

Our analysis of ENCOVID-19 survey data found that $67.3 \%$ of people living in households with children under
3 years of age believed that mothers with COVID-19 should not breastfeed, and $19.8 \%$ reported that they did not know if mothers with COVID-19 should breastfeed. 
Table 5 Results from the SWOT analysis

\begin{tabular}{ll}
\hline Strengths & - Follow-up of the World Breastfeeding Week's activities \\
- Recommendations to keep breastfeeding during the pandemic & - Mexican Ministry of Health's efforts to promote breastfeeding during the pandemic \\
- Comments about the importance of breastfeeding from Mexican Ministry of Health's and UNICEF's experts \\
- Lack of female representation in decision-making at the policy level and in breastfeeding events \\
- Lack of meaningful public policies to protect breastfeeding \\
- Separation of mother-infant dyads during the birth hospitalization period during the COVID-19 pandemic \\
- UN agencies' general nutrition recommendations during the pandemic, and breastfeeding highlighted as \\
a measure to combat food vulnerability and insecurity \\
- New Cooperation Program between UNICEF Mexico and the Mexican government for the 2020-2025 \\
period, where breastfeeding protection and promotion can be incorporated \\
- Non-governmental organizations' demands to regulate BMS donations during the pandemic, which were \\
promoted by pharmacies and BMS companies to the general public \\
- Increase of marketing of BMS during the pandemic \\
- Employment and household work inequities during lockdown measures (i.e., women taking a dispropor- \\
tionate role in caring for children) \\
$\cdot$ - Increasing C-section rates, which are associated with reduced breastfeeding \\
- Influence of medical doctors on women's decisions not to breastfeed
\end{tabular}

a SWOT refers to strengths, weakness, opportunities, and threats

${ }^{b}$ Evidence of marketing was found through an examination of documents/programs referring to promotional marketing materials, but not through an assessment of advertisments

Notably, the proportion of women who thought mothers should not breastfeed was higher than the proportion of men with this belief. Furthermore, more men reported that they did not know if mothers with COVID-19 should breastfeed than women (see Fig. 3). Beliefs about breastfeeding during the COVID-19 pandemic did not differ according to age.

A larger proportion of adults living in households with low and medium-low socio-economic status believed that mothers with COVID-19 should not breastfeed (72.2 and $75.2 \%$, respectively) compared with adults living in households with medium-high and high socio-economic status (56.9 and 53.3\%, respectively) (Fig. 4). Among adults from households with high socioeconomic status, only a minority of them believed that mothers with COVID-19 should breastfeed (26.7\%). The proporition of adults who did not know the answer ranged from $11 \%$ in households with low socioeconomic status to $24.8 \%$ in households with medium-high socioeconomic status (Table 6).

Most adults who believed that women infected with COVID-19 should not breastfeed, reported that the reason why mothers should not do so was because "the virus is transmitted by milk" (62.4\%). About a quarter ((23.7\%)

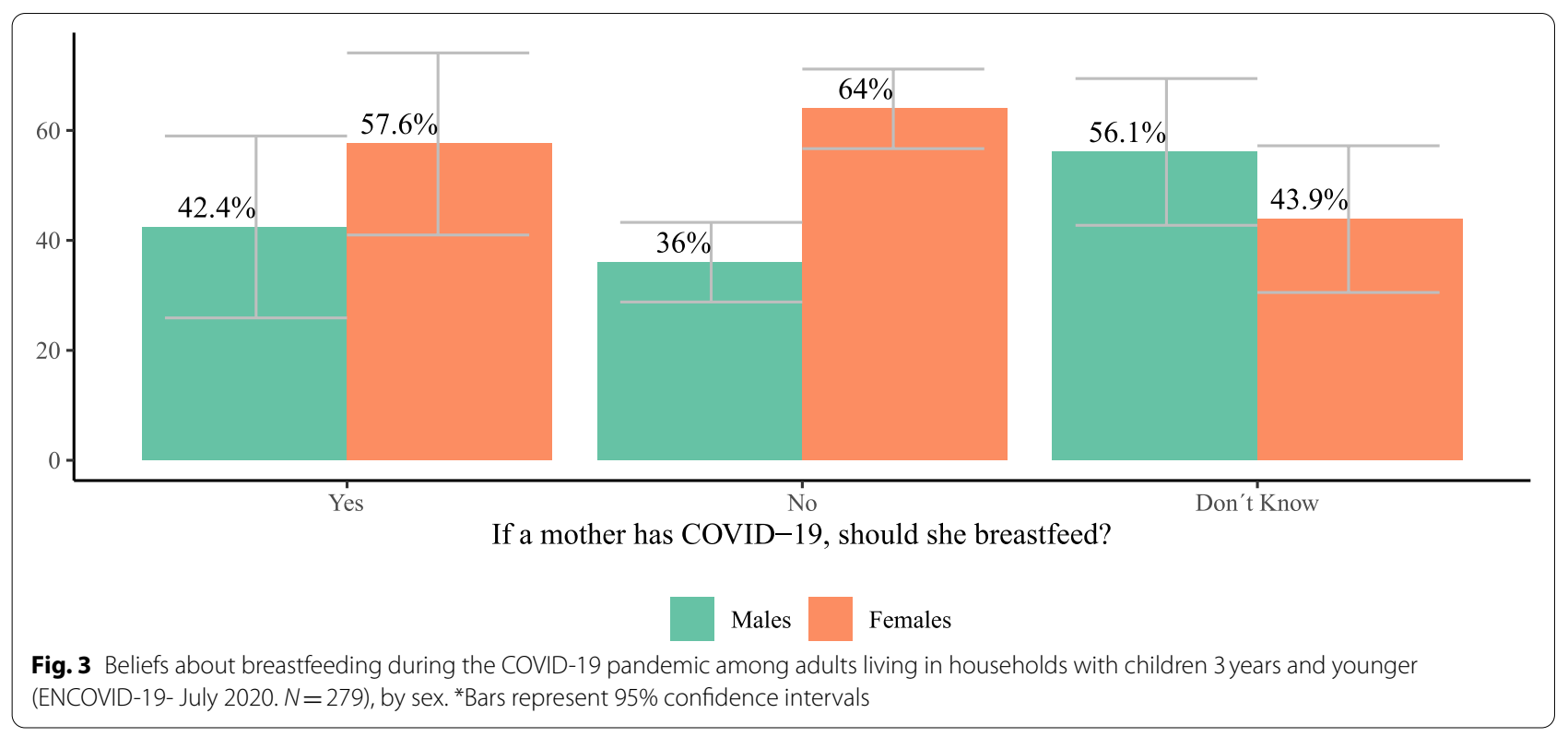




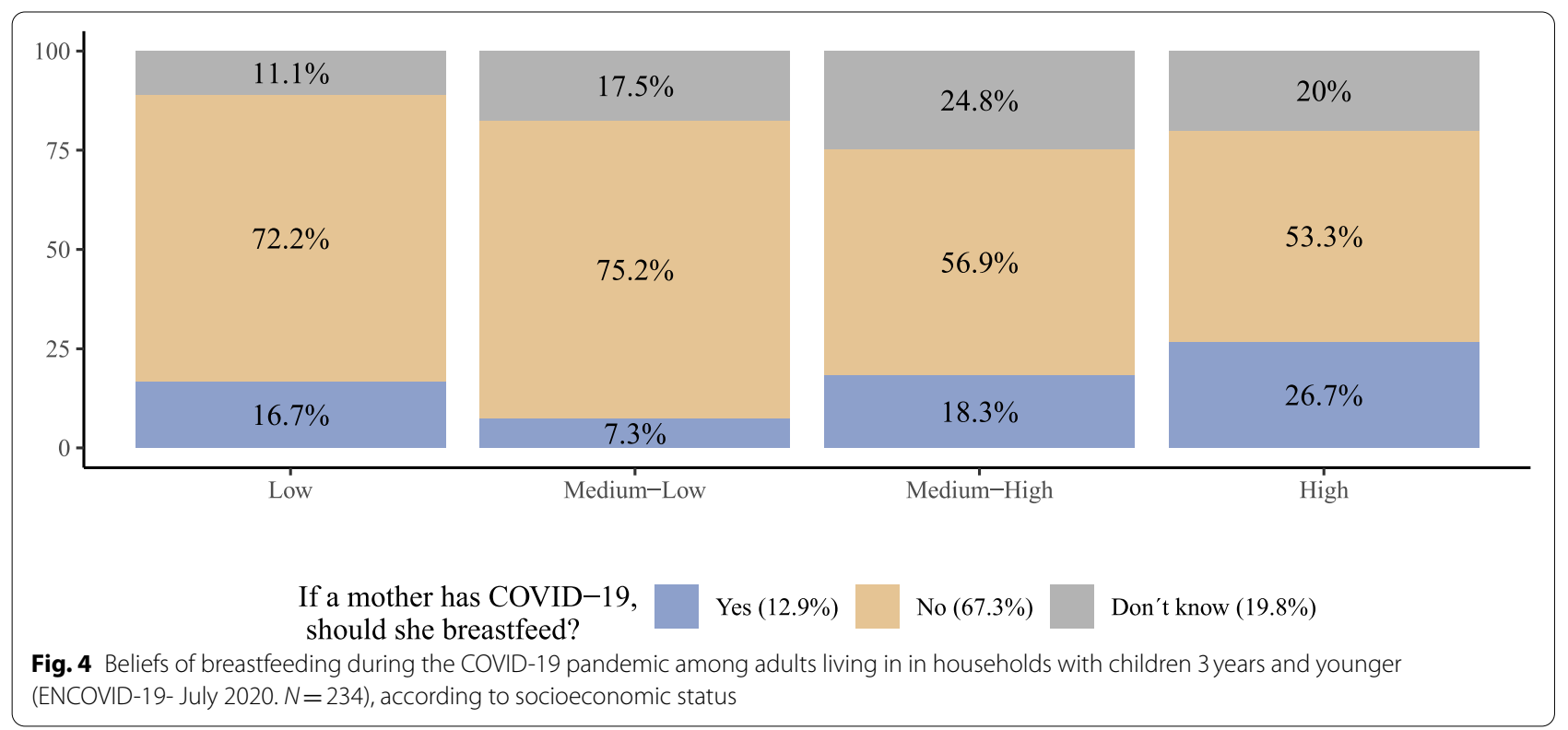

Table 6 Beliefs about breastfeeding during the COVID-19 pandemic among adults living in households with children 3 years and younger (ENCOVID-19- July 2020. N=279), according to socio-economic status

\begin{tabular}{lllll}
\hline & No & Yes & Don't Know & Total \\
\hline Low & $72.2 \%(13)$ & $16.7 \%(3)$ & $11.1 \%(2)$ & 18 \\
Medium-Low & $75.2 \%(103)$ & $7.3 \%(10)$ & $17.5 \%(24)$ & 137 \\
Medium-High & $56.9 \%(62)$ & $18.3 \%(20)$ & $24.8 \%(27)$ & 109 \\
High & $53.3 \%(8)$ & $26.7 \%(4)$ & $20 \%(3)$ & 15 \\
& 186 & 37 & 56 & 279 \\
\hline
\end{tabular}

Note: Socioeconomic status group differences by response to COVID-19 are statistically significant (Kruskal-Wallis chi-squared $=8.7655, \mathrm{df}=3$, $p$-value $=0.033$ ). Post-hoc analyses with the Holm adjustments indicate that the difference between medium-low and medium-high is statistically significant $(p=0.037)$. Fisher's exact test also indicated a statistically significant association (chi-squared $=13.893, \mathrm{df}=6, p$-value $=0.031$ )

of adults reported that the "mother should be isolated." A small proportion of adults reported that their "physician recommended not to" (1.6\%), while $12.4 \%$ said their belief was due to "Other" reasons.

\section{Discussion}

The COVID-19 pandemic is posing challenges to breastfeeding. Evidence supports the continuation of direct breastfeeding, skin-to-skin contact, and not separating the mother-infant dyad during the birth hospitalization even if mothers are infected by SARS-CoV-2. Despite such evidence, it has been hard to combat the public's unsubstantiated fears of infection that arose due to initial inconsistencies in guidance on breastfeeding during the pandemic. In addition, the early controversy regarding the inclusion of pregnant and breastfeeding women in the COVID-19 vaccination schemes could have also affected breastfeeding decisions.

This study offers important lessons from Mexico, which might be relevant for other countries. First, as shown by our analysis of media coverage, traditional media platforms (i.e., magazines, newspapers, TV, radio) disseminated messages released by the government and health organizations experts backing the recommendations of the WHO to directly breastfeed infants even if mothers test positive for SARS-CoV-2. The messages from experts were mainly derived from press conferences, interviews, and governmental reports and guidelines that were subsequently disseminated by media.

Second, despite the recognition and adherence to WHO recommendations by the government and key professional bodies, the media analysis revealed that the promotion of such messages was unevenly distributed by type of media platform. This finding is important because women from different socioeconomic backgrounds and educational levels may be exposed to different media platforms. While almost all of the information regarding breastfeeding was distributed in online versions of traditional media (newspaper, magazines, radio and television), access to internet is deeply unequal by type of location (i.e., urban or rural), gender, education level, occupation, and socioeconomic status in Mexico [58]. There is a difference of 70.7 percentage points in access to 
internet connection between households with high and low socioeconomic status in Mexico. The gap in access to public television and radio is far smaller, with a difference of only 13.9 and 8.8 percentage points, respectively. Although public television is the most used and evenly distributed type of media in the country, most information on breastfeeding was found in online versions, which has the widest distribution gap by socioeconomic status. Therefore, vulnerable households with poor access to internet may be less likely to receive such information. This study also revealed an imbalanced distribution of messages across time, as most messages were distributed during World Breastfeeding Week in August; during this period a high number of positive messages were disseminated. The World Breastfeeding Week is a communication opportunity, but if dissemination is not continuous throughout the year, breastfeeding is at risk of losing salience in the public agenda and public opinion. Informing families about infant feeding choices amidst a pandemic, probably requires a more constant strategy.

Third, the media analysis showed the presence of marketing strategies of BMS during the COVID-19 pandemic. This finding is consistent with findings from studies in other regions during the same period, which show that BMS companies are capitalizing on fear of breastfeeding during the pandemic to market their products [59]. Such strategies to promote and distribute BMS during emergencies such as earthquakes $[60,61]$ and tsunamis [62] have been documented internationally [63]. Together, this evidence highlights that governments and international organizations need to step in to regulate BMS donations and guard mothers and infants against unnecessary promotion and distribution of BMS, which often reaches the most vulnerable populations. For this reason, the World Health Assembly urges all Member States to ensure evidence-based and appropriate infant and young child feeding during emergencies [64].

Lastly, results from our analysis of ENCOVID-19 data showed that most adults believed that an infant should not be breastfed if the mother is infected with COVID19. Such beliefs were more common among lower socioeconomic groups, which could indeed lead to inequities in breastfeeding during a public health emergency. This is worrisome in light of the increased prevalence of food insecurity in Mexico during the pandemic, which has disproportionately affected lower socioeconomic status groups [47]. Decreases in breastfeeding rates can exacerbate household food insecurity due to the high costs of BMS. Furthermore, formula feeding is associated with increased morbidities in infants and young children. Prior studies have also documented increased risk of SARS-CoV-2 infection among low income households due to inequities in housing, employment, and transportation $[65,66]$. Thus, pregnant and lactating mothers living in low income households may be at increased risk of infection, which in turn may imply and increase risk of infection that can discourage them from initiating and continuing breastfeeding.

Our findings indicate that breastfeeding promotion, protection, and support strategies must be prioritized by health professionals, the government, and advocacy groups targeting pregnant women and breastfeeding mothers of vulnerable socioeconomic groups in order to provide accurate information about breastfeeding during the pandemic to mothers and families. There is a need to implement evidence-based and consistent messaging through diverse types of media platforms, combined with strong breastfeeding protection, promotion, and support in clinics and hospitals. Governments are facing unprecedented challenges in providing health services amidst the pandemic, nonetheless, infant and young child feeding information and services during the COVID-19 pandemic need to be prioritized to avoid growing inequities in breastfeeding.

This study uses a novel mixed-methods approach that could be easily and rapidly deployed in other countries. The media analysis identified how breastfeeding recommendations were promoted and disseminated, as well as the limtiations of such process. The telephone survey captured beliefs about breastfeeding during the pandemic among members of families with children under 3 years of age. Our analyses documented breastfeeding promotion and belief gaps linked to barriers of media coverage and, potentially, to other determinants, including misinformation disseminated in social media, lack of adherence of health care providers to guidelines, and the normalization of formula feeding in the country. These determinants should be further studied.

Based on the findings of this study, there are four lessons that can inform communication around breastfeeding during future heath crises. First, it is important to use different media platforms to communicate messages about breastfeeding to mothers and caregivers. The messages need to be consistent and frequent; and, ideally, they should not only provide information but also potential solutions to face the challenges imposed by the crisis. In addition, messages and communication platforms should reach mothers and caregivers throughout all socioeconomic levels and cultural backgrounds. Second, scientific and evidence-based messages need to be communicated rapidly and efficiently to counteract misinformation. While the current study only focused on traditional media platforms, it is important to consider the role of social media in the rapid spread of mis/ 
information that can affect the beliefs about breastfeeding in critical periods. A rapid response can also limit the impact of common promotions and donations of the BMS industry. Lastly, because health providers play a key role in informing mothers and caregivers about breastfeeding, communication strategies should also target them. For example, while the Mexican Government published clear guidelines that adhered to WHO recommendations, there were no targeted communication efforts to disseminate the key practices through traditional media platforms, hence, limiting the implementation at the clinical level. Finally, as highlighted in prior studies during crises and emergencies [60], governments need to have clearer protocols on how to enforce and monitor the protection and support of breastfeeding when such events arise.

This study had several limitations. First, the media analysis excluded social media (i.e. Twitter). Evaluating messages spread through social media could offer a different perspective on information about breastfeeding being disseminated during the COVID-19 pandemic. Such analyses require a different methodological approach than the one employed in this study, for example, network analysis. Second, the ENCOVID-19 sample is cross-sectional, precluding drawing causal inferences. Another limitation is that the media analysis was not able to capture the relative influence of messages in shaping beliefs. For example, during the pandemic a positive message about breastfeeding from the government might have had a different impact on beliefs than a negative message from stakeholders such as pediatricians, family members, or friends [67]. Furthermore, a limitation of the telephone survey is the limited coverage; in 2019, in Mexico, $89.4 \%$ had a mobile phone, but it decreased to $74 \%$ in rural areas [68]. In addition, we cannot ascertain if beliefs about breastfeeding might have changed throughout the pandemic. Future rounds of the ENCOVID-19 should include questions on beliefs about breastfeeding so that future studies can investigate whether and how these beliefs change over time.

\section{Conclusions}

The COVID-19 pandemic has impacted families with infants and young children in many ways, among them, the decisions on how to feed them. In Mexico, the pandemic has dispproportionately affected infants and children from lower socio-economic households. The Mexican government publicly adhered and communicated the WHO recommendations on breastfeeding during the COVID-19 pandemic. Messages appeared in different types of media platforms. However, communication was sporadic, inconstant and unequal across different types of media. In addition, the media analysis revealed that while the government was promoting breastfeeding, there were other media messages linked to donations and promotion of BMS that violate the International Code of Marketing of Breastmilk Substitutes. The survey on breastfeeding beliefs during the pandemic among adults living in households with children under 3 years reveals the widespread notion that, if a mother is infected with COVID-19, she should not breastfeed. This belief was more prevalent among socio-economically disadvantaged families, which could be at higher risk of not initiating or continuing breastfeeding during the pandemic. This health inequity should be addressed through targeted actions. From a policy perspective, it is fundamental to consider that social inequities increase the risk of poorer breastfeeding practices and of not receiving the short and long-term health benefits of breastfeeding.

\section{Abbreviations \\ AMAI: Mexican Association of Market and Opinion Intelligence Agencies (for its acronym in Spanish); BMS: Breastmilk substitutes; ENCOVID-19: Survey on COVID-19 Effects on Wellness in Mexican Households (for its acronym in Span- ish); GILPALM: Permanent Interinstitutional Support Group for Breastfeeding (for its acronym in Spanish); NGO: Non-governmental organization; SARS- CoV-2: Severe acute respiratory syndrome coronavirus 2; SWOT: Strengths, weaknesses, opportunities, threats; UN: United Nations; UNICEF: United Nations Children's Fund; UK: United Kingdom; USA: United States of America; WHO: World Health Organization.}

\section{Acknowledgements}

The authors would like to thank Eficiencia Informativa for their work with the media coverage analysis, as well as Natalia Rovelo for her support in the media analysis data management. We made extensive use of the COVID-19, Breastfeeding, Infant Feeding, and Breast Milk repository and would like to thank the Johns Hopkins Center for Humanitarian Health for this initiative.

\section{Authors' contributions}

MVC led and coordinated this project. MVC, PGR and VCV conducted the analyses, ECR and RPE designed the questions included in the ENCOVID-19 for breastfeeding, MVC wrote the article with support of VCV and all co-authors critically reviewed and made contributions to it. The author(s) read and approved the final manuscript.

\section{Funding \\ This work was supported by a grant for the Research Center for Equitable Development (EQUIDE) at Universidad Iberoamericana devoted to measure the Becoming Breastfeeding Friendly Index Mexico 2020 (PI: Mireya Vilar- Compte). Elizabeth C. Rhodes was supported by grant number K12HL138037 from the National Heart, Lung and Blood Institute. The content is solely responsibility of the authors and does not necessarily represent the official views of the National Heart, Lung, and Blood Institute.}

\section{Availability of data and materials}

The media analysis datasets used during the current study are available from the corresponding author on reasonable request.

The ENCOVID-19 datasets used during the current study are available in the Zenodo repository, on the following link: https://doi.org/10.5281/zenodo. 4602374.

\section{Declarations}

Ethics approval and consent to participate

The ENCOVID-19 project was approved by the Ethics Committee from Universidad Iberoamericana (CONBIOÉTICA-09-CEI-008-2016060). 


\section{Consent for publication \\ Not applicable.}

\section{Competing interests}

The authors declare that they have no competing interests.

\begin{abstract}
Author details
1 Department of Public Health, Montclair State University, University Hall 4157, 1 Normal Ave, Montclair, NJ 07043, USA. ${ }^{2}$ Yale School of Public Health, 135 College St, New Haven, CT 06510, USA. ${ }^{3}$ Yale School of Medicine, 333 Cedar St, New Haven, CT 06510, USA. ${ }^{4}$ Research Center for Equitable Development EQUIDE, Universidad Iberoamericana, Prolongación Paseo de la Reforma 880, Lomas de Santa Fe, 01219 Mexico City, Mexico.
\end{abstract}

\section{Received: 14 May 2021 Accepted: 5 November 2021}

Published online: 20 December 2021

\section{References}

1. Victora CG, Bahl R, Barros AJ, França GV, Horton S, Krasevec J, et al. Breastfeeding in the 21st century: epidemiology, mechanisms, and lifelong effect. Lancet. 2016;387(10017):475-90.

2. Rollins NC, Bhandari N, Hajeebhoy N, Horton S, Lutter CK, Martines JC, et al. Why invest, and what it will take to improve breastfeeding practices? Lancet. 2016;387(10017):491-504.

3. Hand IL, Noble L. Covid-19 and breastfeeding: what's the risk? J Perinatol. 2020;40(10):1459-61.

4. More K, Chawla D, Murki S, Tandur B, Deorari AK, Kumar P. Outcomes of neonates born to mothers with coronavirus disease 2019 (COVID-19)-National Neonatology Forum (NNF) India COVID-19 registry. Indian Pediatr. 2021;58(6):525-31.

5. Kumar J, Meena J, Yadav A, Kumar P. SARS-CoV-2 detection in human milk: a systematic review. J Matern Fetal Neonatal Med. 2021:1-8. https:// doi.org/10.1080/14767058.2021.1882984.

6. BRD C, KdS A, Gonçalves-Ferri WA, Samama M, Ferriani RA, Marcolin AC. COVID-19: uncertainties from conception to birth. Revista Brasileira de Ginecologia e Obstetrícia. 2021;43(1):54-60.

7. Shlomai NO, Kasirer Y, Strauss T, Smolkin T, Marom R, Shinwell ES, et al. Neonatal SARS-CoV-2 infections in breastfeeding mothers. Pediatrics. 2021;147(5):e2020010918.

8. Chambers C, Krogstad P, Bertrand K, Contreras D, Tobin NH, Bode L, et al. Evaluation for SARS-CoV-2 in breast milk from 18 infected women. JAMA. 2020;324(13):1347-8.

9. Groß R, Conzelmann C, Müller JA, Stenger S, Steinhart K, Kirchhoff F, et al. Detection of SARS-CoV-2 in human breastmilk. Lancet. 2020;395(10239):1757-8.

10. Tam PC, Ly KM, Kernich ML, Spurrier N, Lawrence D, Gordon DL, et al. Detectable severe acute respiratory syndrome coronavirus 2 (SARS(oV-2) in human breast milk of a mildly symptomatic patient with coronavirus disease 2019 (COVID-19). Clin Infect Dis. 2021;72(1):128-30.

11. Costa S, Posteraro B, Marchetti S, Tamburrini E, Carducci B, Lanzone A, et al. Excretion of SARS-CoV-2 in human breast milk. Clin Microbiol Infect. 2020;26(10):1430-2.

12. Cheema R, Partridge E, Kair LR, Kuhn-Riordon KM, Silva Al, Bettinelli ME, et al. Protecting breastfeeding during the COVID-19 pandemic. Am J Perinatol. 2020:s-0040-1714277.

13. Gribble K, Marinelli KA, Tomori C, Gross MS. Implications of the COVID-19 pandemic response for breastfeeding, maternal caregiving capacity and infant mental health. J Hum Lact. 2020;36(4):591-603.

14. Dong $Y$, Chi $X$, Hai H, Sun L, Zhang M, Xie W-F, et al. Antibodies in the breast milk of a maternal woman with COVID-19. Emerg Microbes Infect. 2020;9(1):1467-9.

15. Fox A, Marino J, Amanat F, Krammer F, Hahn-Holbrook J, Zolla-Pazner $\mathrm{S}$, et al. Evidence of a significant secretory-IgA-dominant SARS-CoV-2 immune response in human milk following recovery from COVID-19. MedRxiv. 2020.

16. Yu JC, Khodadadi H, Salles ÉL, Pham Q, Patel P, Baban B. High levels of interferon-alpha expressing macrophages in human breast Milk during SARS-CoV-2 infection: a case report. Breastfeed Med. 2021;16(5):439-42
17. Demers-Mathieu V, DaPra C, Mathijssen GB, Medo E. Previous viral symptoms and individual mothers influenced the leveled duration of human milk antibodies cross-reactive to S1 and S2 subunits from SARS-CoV-2, HCoV-229E, and HCoV-OC43. J Perinatol. 2021;41(5):952-60.

18. Zhu F, Zozaya C, Zhou Q, De Castro C, Shah PS. SARS-CoV-2 genome and antibodies in breastmilk: a systematic review and meta-analysis. Arch Dis Child Fetal Neonatal Ed. 2021.

19. Pace RM, Williams JE, Järvinen KM, Belfort MB, Pace CD, Lackey KA, et al. Characterization of SARS-CoV-2 RNA, antibodies, and neutralizing capacity in milk produced by women with COVID-19. Mbio. 2021;106(5):514-21.

20. Golan Y, Prahl M, Cassidy A, Wu AH, Jigmeddagva U, Lin CY, et al. Immune response during lactation after anti-SARS-CoV2 mRNA vaccine. medRxiv. 2021:12:1-12.

21. Friedman MR, Kigel A, Bahar Y, Yogev Y, Dror Y, Many A, et al. BNT162b2 COVID-19 mRNA vaccine elicits a rapid and synchronized antibody response in blood and milk of breastfeeding women. medRxiv. 2021.

22. Paul G, Chad R. Newborn antibodies to SARS-CoV-2 detected in cord blood after maternal vaccination-a case report. BMC Pediatr. 2021:21(1):1-2.

23. Gray KJ, Bordt EA, Atyeo C, Deriso E, Akinwunmi B, Young N, et al. COVID19 vaccine response in pregnant and lactating women: a cohort study. Am J Obstet Gynecol. 2021;225(3):303.e1-303.e17.

24. Davanzo R, Agosti M, Cetin I, Chiantera A, Corsello G, Ramenghi LA, et al. Breastfeeding and COVID-19 vaccination: position statement of the Italian scientific societies. Ital J Pediatr. 2021;47(1):1-4.

25. Golan Y, Prahl M, Cassidy A, Lin CY, Ahituv N, Flaherman VJ, et al. COVID-19 mRNA vaccine is not detected in human milk. medRxiv. 2021.

26. Williams J, Namazova-Baranova L, Weber M, Vural M, Mestrovic J, Carrasco-Sanz A, et al. The importance of continuing breastfeeding during coronavirus disease-2019: in support of the World Health Organization statement on breastfeeding during the pandemic. J Pediatr. 2020;223:234

27. Lubbe W, Botha E, Niela-Vilen H, Reimers P. Breastfeeding during the COVID-19 pandemic-a literature review for clinical practice. Int Breastfeed J. 2020;15(1):1-9.

28. WHO. Clinical management of severe acute respiratory infection when novel coronavirus (nCoV) infection is suspected. 2020. https://www.who. int/publications-detail/clinical-management-of-severe-acute-respiratoryinfection-when-novel-coronavirus-(ncov)-infection-is-suspected. : World Health Organization; 2020.

29. Rollins N, Minckas N, Jehan F, Lodha R, Raiten D, Thorne C, et al. A public health approach for deciding policy on infant feeding and mother-infant contact in the context of COVID-19. Lancet Glob Health. 2021:9(4):e552-e557.

30. Del Río R, Dip Pérez E, Marín Gabriel MÁ, Group NCR. Multi-Centre study showed reduced compliance with the World Health Organization recommendations on exclusive breastfeeding during COVID-19. Acta Paediatr. 2021:110(3):935-6.

31. Hoang DV, Cashin J, Gribble K, Marinelli K, Mathisen R. Misalignment of global COVID-19 breastfeeding and newborn care guidelines with World Health Organization recommendations. BMJ Nutr Prev Health. 2020:3(2):339.

32. Brown A, Shenker N. Experiences of breastfeeding during COVID-19: lessons for future practical and emotional support. Matern Child Nutr. 2021;17(1):e1`3088.

33. Sola A, Rodríguez S, Cardetti M, Dávila C. COVID-19 perinatal en América Latina. Rev Panam Salud Publica. 2020:44:e47.

34. Mayo S, Monfort S. Breastfeeding and COVID-19 vaccine: yes we can. J Hum Lact. 2021:08903344211004443:275-6.

35. Government PoM. COVID-19 Vaccine: Information for Pregnant and Breastfeeding Individuals. 2021 https://www.gov.mb.ca/asset_library/en/ covidvaccine/covid19_vaccine_pregnant.pdf.

36. NHS. COVID-19 vaccination consent form. 2021. https://assets.publishing service.gov.uk/government/uploads/system/uploads/attachment_data/ file/954440/PHE_Covid-19_consent_form_adults_able_to_consent_v2.pdf.

37. Merewood A, Bode L, Davanzo R, Perez-Escamilla R. Breastfeed or be vaccinated - an unreasonable default recommendation. Lancet. 2021;397(10274):578

38. Hare H, Womersley K. Why were breastfeeding women in the UK denied the covid-19 vaccine? BMJ. 2021:372:n4. 
39. Managing the COVID-19 infodemic: Promoting healthy behaviours and mitigating the harm from misinformation and disinformation [press release]. https://www.who.int/news/item/23-09-2020-managing-thecovid-19-infodemic-promoting-healthy-behaviours-and-mitigating-theharm-from-misinformation-and-disinformation: WHO2020.

40. Moukarzel S, Del Fresno M, Bode L, Daly AJ. Distance, diffusion and the role of social media in a time of COVID contagion. Matern Child Nutr. 2020;16(4):1-4.

41. Pérez-Escamilla R, Curry L, Minhas D, Taylor L, Bradley E. Scaling up of breastfeeding promotion programs in low-and middle-income countries: the "breastfeeding gear" model. Adv Nutr. 2012;3(6):790-800.

42. Bou-Karroum L, El-Jardali F, Hemadi N, Faraj Y, Ojha U, Shahrour M, et al. Using media to impact health policy-making: an integrative systematic review. Implement Sci. 2017;12(1):1-14.

43. Bryant, Jennings, and Mary Beth Oliver, eds. Media effects: Advances in theory and research. New York: Routledge; 2009.

44. Pérez-Escamilla, R, Cunningham, K, Moran, VH. COVID-19 and maternal and child food and nutrition insecurity: a complex syndemic. Matern Child Nutr. 2020; 16:e13036. https://doi.org/10.1111/mcn.13036.

45. Patil UP, Maru S, Krishnan P, Carroll-Bennett R, Sanchez J, Noble L, et al. Newborns of COVID-19 mothers: short-term outcomes of colocating and breastfeeding from the pandemic's epicenter. J Perinatol. 2020;40(10):1455-8.

46. WHO. WHO Coronavirus (COVID-19) Dashboard. Geneva: World Health Organization; 2021. https://covid19.who.int/table.

47. Gaitán-Rossi P, Vilar-Compte M, Teruel G, Pérez-Escamilla R. Food insecurity measurement and prevalence estimates during the COVID-19 pandemic in a repeated cross-sectional survey in Mexico. Public Health Nutr. 2020;24(3):412-21.

48. Vilar-Compte M, Hernandez-F M, Gaitán-Rossi P, Pérez V, Teruel G. Associations of the COVID-19 pandemic with social wellbeing indicators in Mexico; 2021

49. Gaitán-Rossi P, Pérez-Hernández V, Vilar-Compte M, Teruel-Belismelis G. Monthly prevalence of generalized anxiety disorder during the COVID-19 pandemic in Mexico. Salud Publica Mex. 2021;63(4):478-85.

50. Rivera-Dommarco J, Bonvecchio-Arenas A, Quezada-Sánchez AD, UnarMunguía M, González-Castell LD. Breastfeeding and complementary feeding practices in Mexico: results from Ensanut 2018-19. Salud Publica Mex. 2020;62(6):704-13.

51. Gonzalez de Cosio T, Escobar-Zaragoza L, La G-C, Rivera-Dommarco JÁ. Infant feeding practices and deterioration of breastfeeding in Mexico. Salud publica de Mexico. 2013;55:S170-9.

52. México Gd. Lineamiento para la prevención y mitigación de COVID-19 en la atención del embarazo, parto, puerperio y de la persona recién nacida. 2020 https://coronavirus.gob.mx/wp-content/uploads/2020/07/Linea mientos_Prevencion_COVID19_Embarazos_V2.pdf;.

53. Perinatology Nlo. Ineamiento Técnico del Abordaje del paciente con infección por COVID-19 en el periodo perinatal. 2020.https://inper.mx/ descargas-2019/pdf/LineamientoINPerCOVID19_2.pdf;.

54. Pediatria AMd. Guía informativa sobre COVID-19 para padres de familia y tutores en base a la información surgida de la pandemia. Mexico: Asociación Mexicana de Pediatria; 2020.

55. Health Mo. Estrategia Nacional de Lactancia Materna 2014-2018. 2014 http://cnegsr.salud.gob.mx/contenidos/descargas/SMP/ENLM_20142018.pdf;.

56. Ferré-Eguiluz I, Buccini G, Hromi-Fiedler A, Rovelo N, González de Cosío T, Pérez-Escamilla-Costas JR, et al. Content analysis of media coverage of breastfeeding in Mexico. Matern Child Nutr. 2020;16(2):e12905.

57. AMAI. Nivel Socioeconómico AMAI. Nota Metodológica. Asociacion Mexicana de Agencias de Inteligencia Mercado y Opinion: Mexico; 2018.

58. Telecomunicaciones IFd. Uso de las TIC y actividades por internet en México: impacto de las características sociodemográficas de la población. 2019 http://www.ift.org.mx/sites/default/files/contenidogeneral/estad isticas/usodeinternetenmexico.pdf.

59. Ching C, Zambrano P, Nguyen TT, Tharaney M, Zafimanjaka MG, Mathisen R. Old tricks, new opportunities: how companies violate the international code of Marketing of Breast-Milk Substitutes and Undermine Maternal and child health during the COVID-19 pandemic. Int J Environ Res Public Health. 2021;18(5):2381.
60. Vilar-Compte M, Navarro CP, Burrola-Méndez S, Sachse-Aguilera M, Veliz P. Barriers and enablers of breast-feeding protection and support after the 2017 Earthquakes in Mexico. Public Health Nutr. 2020;24:1-11.

61. Hipgrave DB, Assefa F, Winoto A, Sukotjo S. Donated breast milk substitutes and incidence of diarrhoea among infants and young children after the may 2006 earthquake in Yogyakarta and Central Java. Public Health Nutr. 2012;15(2):307-15.

62. Adhisivam B, Srinivasan S, Soudarssanane M, Deepak Amalnath S, Nirmal $K A$. Feeding of infants and young children in tsunami affected villages in Pondicherry. Indian Pediatr. 2006;43(8):724.

63. Rawas S. Challenges of dealing with unsolicited donations during emergencies. Field Exch. 2008;34:41.

64. UNICEF W. Global nutrition targets 2025: breastfeeding policy brief (WHO/NMH/NHD/14.7). Geneva: World Health Organization; 2014.

65. Rodriguez-Diaz CE, Guilamo-Ramos V, Mena L, Hall E, Honermann B, Crowley JS, et al. Risk for COVID-19 infection and death among Latinos in the United States: examining heterogeneity in transmission dynamics. Ann Epidemiol. 2020;52:46-53. e2.

66. Hooper MW, Nápoles AM, Pérez-Stable EJ. COVID-19 and racial/ethnic disparities. JAMA. 2020;323(24):2466-7.

67. Wallenborn JT, Wheeler DC, Lu J, Perera RA, Masho SW. Importance of familial opinions on breastfeeding practices: differences between father, mother, and mother-in-law. Breastfeed Med. 2019;14(8):560-7.

68. INEGI. Encuesta Nacional sobre Disponibilidad y Uso de Tecnologías de la Informacion en los Hogares (ENDUTIH) (National Survey of Households' Availability and Use of Information Technology). https://www.inegi.org. mx/programas/dutih/2019/ (accessed June 2020). 2019 programas/ dutih/2019/ (accessed Jun 2020).

\section{Publisher's Note}

Springer Nature remains neutral with regard to jurisdictional claims in published maps and institutional affiliations.

Ready to submit your research? Choose BMC and benefit from:

- fast, convenient online submission

- thorough peer review by experienced researchers in your field

- rapid publication on acceptance

- support for research data, including large and complex data types

- gold Open Access which fosters wider collaboration and increased citations

- maximum visibility for your research: over 100M website views per year

At BMC, research is always in progress.

Learn more biomedcentral.com/submissions 